\title{
O QUE MOVE A AÇÃO DOS INDIVÍDUOS? UM DIÁLOGO COM PIERRE BOURDIEU E FRANÇOIS DUBET
}

\author{
WHAT MOVE THE ACTION OF INDIDUALS? A DIALOGUE WITH BOURDIEU AND \\ FRANCOIS DUBET \\ ¿QUÉ MUEVE LA ACCIÓN DE LOS INDIVIDUOS? UN DIÁLOGO CON PIERRE BOURDIEU Y \\ FRANÇOIS DUBET
}

Deise Arenhart

Doutora em Educação. Professora adjunta da Faculdade de Educação da UFRJ | Brasil E-mail: deise.arenhart@hotmail.com

REVISTA PEDAGÓGICA

Revista do Programa de Pós-graduação em Educação da Unochapecó | ISSN 1984-1566

Universidade Comunitária da Região de Chapecó | Chapecó-SC, Brasil Como referenciar este artigo: ARENHART, D. O que move a ação dos indivíduos? Um diálogo com Pierre Bourdieu e François Dubet. Revista Pedagógica, Chapecó, v.16, n.33, p. 335-348, Jul./Dez. 2014.

RESUMO: A idéia deste texto é apresentar e discutir os conceitos centrais de dois autores que têm se preocupado em entender os processos da ação e/ou reprodução social a partir de pontos de vistas diferentes: Pierre Bourdieu e François Dubet. Para o primeiro, o que explica a ação dos indivíduos, a qual sempre caminha no sentido da reprodução, é a existência do habitus. Já para o segundo, o indivíduo tem maior papel de autoria em suas ações e as constrói através da experiência. Refletindo o sentido da escola para os dois autores, indica-se que, para Bourdieu, a escola produz desigualdades e contribui para a reprodução social. Já para Dubet, o sentido da escola é dado pelo ator, no desenrolar de sua experiência escolar.

PALAVRAS-CHAVE: Ação Social. Bourdieu. Dubet. Habitus. Experiência.
ABSTRACT: The idea of this text is to present and discuss the central concepts of two authors that have been concerned to understand the processes of action and/or social reproduction from different points of view: Pierre Bourdieu and François Dubet. For the first one, what explains the action of individuals, which always walk on the way of reproduction, is the existence of the habitus. For the second one, the individual has a bigger authorship role in his actions and constructs them through the experience. Reflecting the meaning of school for both of them, it shows that, according to Bourdieu, it produces inequality and contributes for the social reproduction. For Dubet, the meaning of school is given by the actor in the course of his school experience.

KEYWORDS: Social action. Bourdieu. Dubet. Habitus. Experience. 


\section{INTRODUÇÃO}

O que move a ação dos indivíduos?

A idéia deste texto é apresentar elementos no sentido de buscar responder a esta questão. Farei isso a partir de dois autores que têm se preocupado em entender os processos da ação e/ou reprodução social a partir de pontos de vistas diferentes: Pierre Bourdieu e François Dubet.

Esses dois autores, ambos situados na sociologia francófona, têm entendido a ação humana a partir de dois conceitos fundamentais. Para o primeiro, o que explica a ação dos indivíduos, a qual, sempre caminha no sentido da reprodução, é a existência do habitus. Já para o segundo, o indivíduo tem maior papel de autoria em suas ações e as constrói através da experiência.

Desse modo, o texto está estruturado de forma que, sempre perseguindo a questão que o incita, apresento estes dois conceitos, respectivamente, o habitus em Bourdieu e a experiência em Dubet. Na última parte do texto, busco realizar uma espécie de síntese dos dois autores, relacionando, sucintamente, suas teorias às análises que fazem sobre o sentido da Escola.

Cabe ainda esclarecer que escolhi como base de pesquisa para este trabalho, algumas obras dos autores que tiveram relação mais direta com o recorte feito, bem como outras fontes indiretas.

\section{O CONCEITO DE HABITUS EM PIERRE BOURDIEU}

Bourdieu elabora seu projeto teórico num contexto em que a França estava arraigada na tradição teórica do funcionalismo, estruturalismo existencialismo. Querendo, pois, afastar-se dessa fragmentação entre objetivismo (do estruturalismo e do funcionalismo) e subjetivismo (do existencialismo), Bourdieu procura construir uma teoria que articule estas duas dimensões do social: a estrutura e o sujeito, o geral e o particular, o micro e macro.

Desse modo, ainda que busque elaborar explicações e regras gerais, dando grande peso à estrutura, procura considerar esta não numa relação objetivista, como se a estrutura fosse um sistema fechado, coeso e imutável como o é no funcionalismo - ou como se tudo fosse explicado pelo viés econômico e pela luta de classes - vide marxismo. Mesmo tendo forte influência do estruturalismo, busca afastar-se do funcionalismo de Durkmein e do materialismo de Marx, no sentido em que insere o elemento da cultura na análise da sociedade e no que pensa as classes sociais no sentido relacional e não de antagonismo, ainda que 
considere que a reprodução social se dê pela dominação de uma classe sobre outra.

Desse modo, lançando seu primeiro livro em 1964 Os herdeiros -, seguido de A reprodução (1978), Bourdieu se destaca por construir uma teoria social que inclui uma análise cultural sobre a sociedade e as relações sociais. Em nível macro, admite a existência, para além das classes, de campos sociais e, no micro, analisa que as ações humanas são frutos do habitus.

O habitus, para Bourdieu, refere-se a um conjunto de disposições inconscientes, transferíveis e duradouras que são adquiridas pelo sujeito em seu processo de socialização e que está intimamente ligado ao seu pertencimento de classe. Por sua vez, essas disposições do habitus são formadas pela incorporação dos gostos, costumes, valores, etc... relacionados às condições objetivas de existência do sujeito e que vão constituindo suas inclinações para perceber, sentir, fazer e pensar. Essas disposições, quando incorporadas, se automatizam e passam a ser princípios inconscientes de sua ação (Bourdieu, 1983; Bonnewitz,2005).

Bourdieu ainda define dois componentes que formam o habitus: 1) ethos: relativo aos princípios e valores em estado prático que guiam as ações do indivíduo; a forma interiorizada e não-consciente da moral e 2) hexis: designa as disposições do corpo; modos de se portar, de andar, de se vestir, de falar, etc, também incorporadas inconscientemente pelo processo de socialização no interior da classe de pertença do indivíduo (Bonnewitz, 2005).

O habitus é fruto, pois, da relação entre estrutura social e estrutura mental; fornece a mediação entre o individual e o coletivo. Segundo Bonnewitz (2005), ele é mecanismo de interiorização da exterioridade e exteriorização da interioridade. Portanto, para Bourdieu, a socialização é caracterizada pela formação do habitus. Do mesmo modo, as classes sociais não se definem e não se reproduzem pelo poderio econômico somente, mas por ser um grupo social que compartilha de um mesmo habitus.

Bourdieu ainda classifica o habitus em primário e secundário. $\mathrm{O}$ primeiro, segundo ele, é o mais duradouro e adquirido na primeira infância. As disposições desse (do primário) condicionam a aquisição posterior (do habitus secundário). Porém, Bourdieu fala em condicionamento e, não, em determinação. Isso significa que o habitus não é congelado, está sempre se reestruturando de acordo com as novas condições objetivas em que o sujeito passa a se inserir. A consideração do habitus nessa dimensão de condicionamento é que permite entender que, para Bourdieu, a ação dos indivíduos não está totalmente determinada pelo habitus, mas, nem tão pouco, livre dele. 
1A posição social, segundo Boudieu, está relacionada com o volume de capital que o indivíduo dispõe. Os capitais, por sua vez, estão distribuídos em 4 tipos: econômico, relativo à posse de bens econômicos; cultural, relativo às qualificações intelectuais transmitidas pela família e escola; social, relativo ao conjunto de relações sociais e simbólico, relativo ao reconhecimento da honra do indivíduo pelo conjunto da sociedade. Entre estes capitais, é a posse de capital econômico e cultural que mais confere vantagens ao indivíduo no sentido de diferenciar-se no espaço social. O espaço social, para Bourdieu, é que dá a dimensão relacional, e não piramidal, das posições sociais. Para aprofundar, ver: Bourdieu (1983) e Bonnewitz (2005).

2 Os campos sociais são constituídos por objetos e disputas em comum, com leis funcionais invariantes e propriedades específicas. Assim, temos o campo da política, da religião, da moda, da arte, o campo científico, etc. "Para que um campo funcione, é preciso que haja objetos de disputa e pessoas prontas para disputar o jogo, dotadas de habitus que impliquem no conhecimento e no reconhecimento das leis imanentes do jogo, dos objetos de disputa, etc" (Bourdieu, 1983, p. 89).

3 Bourdieu busca mostrar que os estilos pessoais, na verdade, são produzidos socialmente, fruto muito mais de uma incorporação inconsciente do que de escolhas conscientes e aleatórias feitas pelo sujeito. Não é por acaso, que a tendência das classes sociais é a de relacionarem-se entre si, no interior dela mesma, quer seja com arranjos amorosos, profissionais, sociais ou na identificação quanto a visões políticas, filosóficas, artísticas, de moda, etc...
É, pois, pelo conceito de habitus que Bourdieu busca fazer a mediação entre objetivismo e subjetivismo. O sujeito nem é totalmente autônomo e nem totalmente passivo perante os condicionantes sociais. Porém, ainda que Bourdieu não outorgue ao indivíduo um papel de mero receptáculo dos condicionamentos sociais, como no estruturalismo, ele também limita a ação do sujeito às disposições do habitus. Assim, fala em agente social, no sentido de deixar claro essa relação entre indivíduo e meio social. Para ele, o agente é agido (no interior) tanto quanto age (para o exterior) (Bonnewitz, 2005, p. 82).

É pela formação do habitus de classe que o indivíduo vai se constituindo como sujeito que ocupa determinada posição social ${ }^{1}$; que transita, autonomamente, em determinado campo social $^{2}$, e se movimenta, inconscientemente, conforme as regras do jogo que constituem os campos e a posição social que ocupa. Desse modo, o habitus opera o que Bourdieu denomina de distinção social. Os indivíduos passam se distinguirem socialmente conforme as regras e o 'estilo' estruturado pelo campo e a posição social que ocupam. ${ }^{3}$

Nesse sentido, o habitus, para Bourdieu, éresponsável pela reprodução social, na medida em que o indivíduo incorpora, inconscientemente, as chances objetivas de seu pertencimento de classe, sendo muito improvável, que ele possa sair aos condicionamentos de seu habitus. Ou seja, o habitus harmoniza e naturaliza as escolhas e os arranjos, levando a naturalização dos processos de identificação.

Para Bourdieu (1983, p. 93), pois, "a teoria do habitus visa a fundar a possibilidade de uma ciência das práticas que escape à alternativa do finalismo ou mecanicismo", uma vez que as estratégias sociais dos agentes não são resultado de cálculos conscientes e cínicos, mas sim, resultado de uma "relação inconsciente entre um habitus e um campo"( Bourdieu, 1983, p. 93). Nessa direção, Bourdieu ainda complementa:

O habitus, sistema de disposições adquiridas pela aprendizagem implícita ou explícita que funciona como um sistema de esquemas geradores, é gerador de estratégias que podem ser objetivamente afins aos interesses objetivos de seus autores sem terem sido expressamente concebidas para este fim (Bourdieu, 1983, p. 94).

Em texto intitulado Futuro de classe e causalidade do provável, Bourdieu observa - apoiado em dados estatísticos - uma íntima relação entre as expectativas, as aspirações do sujeito e as suas chances objetivas; uma se define em função da outra. 
4 Segundo Bourdieu, a escola passa a ser estratégia de mobilidade social principalmente para as famílias da pequenaburguesia. Essas, investindo, fortemente em capital cultural, apostam na escola como possibilidade dos filhos virem a cursar o liceu e o ensino superior e, dessa forma, acenderem socialmente. Já as famílias de classes populares se conformam com um sentido utilitarista dessa em ensinar as funções básicas de ler e escrever, uma vez que excluem a possibilidade de desejar o impossível. Para Bourdieu, elas incorporam e se conformam em desejar apenas o possível. "[...] É porque o desejo razoável de ascensão através da escola não pode existir enquanto as chances objetivas forem ínfimas" (Bourdieu, 1998, p. 48).
[...] a concordância das expectativas com as probabilidades, das antecipações com as realizações, está no princípio dessa espécie de 'realismo', enquanto sentido da realidade e senso das realidades que faz com que, para além dos sonhos e das revoltas, cada um tenda a viver 'de acordo com a sua condição', segundo a máxima tomista, e tornar-se inconscientemente cúmplice dos processos que tendem a realizar o provável (Bourdieu, 1998, p. 90,91).

Essa interiorização das chances objetivas desempenha um papel-chave nas estratégias sociais que, segundo ele, são diferentes no interior de cada classe social ${ }^{4}$. Por outro lado, admitir que existam probabilidades que apontam para uma auto-reprodução do futuro das classes, reprodução essa perpetuada pelo habitus, não significa, no entanto, que Bourdieu desconsidere a possibilidade de desvios nessa análise mais geral.

Nesse sentido, a consideração da análise das trajetórias dos agentes que, muitas vezes, se conflitam com as estratégias familiares relativas ao seu ethos social, mostra esse movimento contraditório que resiste à tentativa de considerar o habitus e a posição social como algo estático e imutável. No entanto, preocupado em apresentar leis mais gerais para explicar a reprodução social, Bourdieu não desconsidera, em nenhuma hipótese, que o habitus de classe atua modelando as estratégias e as trajetórias, no sentido de tender à manutenção do sistema capitalista e, assim sendo, classista, por essência.

Outro exemplo que expressa esse movimento de conservação e mudança do habitus se refere ao que Bourdieu denomina como hysteresi. Hysteresi, assim, caracteriza-se como um mal-estar decorrente da inadaptação do habitus a um determinado campo ou posição social, ou seja, mudamse as condições objetivas, mas o habituscontinua o mesmo. O indivíduo passa, então, a viver um conflito gerado pelo choque entre seu habitus primário, formado na classe de origem e o habitus secundário, relativo ao novo campo ou classe social que passou a ocupar. Mesmo que se admita a possibilidade de mudança na posição social - acendendo ou declinando de classe - o mesmo sofrerá esse efeito de hysteresi, dado a força condicionadora do habitus.

Bourdieu é tido como um dos principais sociólogos da contemporaneidade, uma das principais referências do campo da Sociologia da Educação. No entanto, é no interior desse mesmo campo, que também se encontram seus maiores críticos.

Bernard Lahire (1996), sociólogo francês e um dos sucessores de Bourdieu, tem apontado contundentes críticas ao conceito de habitus. Para este autor, o habitus está formulado de forma muito geral e fechada, não 
refletindo as contradições que escapam às regras gerais. Problematiza o caráter do habitus se constituir num sistema de disposições duráveis e transponíveis, pois, para ele, as disposições não necessariamente constituem um sistema, na medida em que podem ser heterogêneas e contraditórias, nem sempre duráveis e transferíveis.

Alega isso a partir de pesquisa empírica realizada no espaço familiar, no que diz que muitas famílias constroem estratégias que são contraditórias às próprias disposições de seu habitus. Como exemplo, menciona a realidade de famílias que, ainda que não tenham um habitus constituído pela posse de capital cultural, nem por isso, deixam de ter disposições favoráveis para a carreira escolar, pois essas são produzidas por outras vias, como por exemplo, a questão da honra.

Assim, defende a necessidade de se explodir o conceito de habitus. Nesse sentido, alega que, mais interessante do que pensar em um sistema de disposições duráveis e transferíveis, seria pensar que o sujeito traz um patrimônio de disposições, nem sempre duráveis e transferíveis em todos os contextos.

Outro autor que também se opõe a Bourdieu é o próprio François Dubet. Porém, a distância desses é ainda maior, visto que têm bases epistemológicas bem distintas. Nesse sentido, não poderia pautar na diferença de paradigma para fazer a crítica à diferença, uma vez que estão em lugares teóricos distintos. Contudo, salvo as divergências epistemológicas, Dubet estende críticas a Bourdieu alegando que, por mais que esse quisesse superar o objetivismo e o subjetivismo, o conceito de habitus, tal qual está formulado, acaba pendendo para o objetivismo. Alega que, mesmo Bourdieu querendo fazer contraposição a Durkmein e Marx, acaba se aproximando desses no que reproduz um sujeito objetivado pelo sistema, mero fruto dos processos de integração. Radicaliza a crítica ao afirmar que, para uma teoria em que o sistema social é tão reduzido á lógica da dominação, o indivíduo passa ser um logro (Dubet, 1996).

\section{O CONCEITO DE EXPERIÊNCIA EM FRAN- ÇOIS DUBET}

Como já anunciado anteriormente, Dubet se contrapõe a Bourdieu por ter outra matriz epistemológica. Tendo filiação a autores interacionistas e fenomenológicos, como Touraine, Weber, Mead, Simmel, Gofmann, entre outros, está preocupado em compreender a ação dos indivíduos numa sociedade pós-industrial.

Realiza sua análise da sociedade moderna contrapondo-se à visão da sociologia clássica, representada por autores como Durkmein, Norbert Elias e Marx, para 
os quais a sociedade ainda funciona como um organismo coeso, organizada pela divisão social do trabalho (Durkmein) e fundada em instituições (como a Família, a Escola, a Igreja). Essas, para os estruturalistas, teriam grande papel na socialização dos indivíduos no sentido de manter a coesão social.

Dubet realiza forte contraposição a essa idéia de sociedade forte e coesa, e, nela, a idéia de um sujeito passivo frente a seus processos de socialização. Contudo, não se assume como pós-moderno, uma vez que não abre mão da racionalidade científico-instrumental para entender a construção do sujeito nessa nova sociedade.

Desse modo, sua teoria está elaborada de forma a contemplar uma análise macro-social, na qual busca fazer uma leitura das novas configurações da sociedade que denomina como pós-industrial, bem como, micro-social, na qual busca compreender como o ator social age, o que move as ações do sujeito e como esse sujeito é construído nessa nova sociedade.

Para tanto, Dubet elabora dois conceitos centrais em sua teoria sociológica: o primeiro - desinstitucionalização - está relacionado à análise da sociedade no plano macro e o segundo - experiência - fundamenta a análise micro, na qual o sujeito e suas relações com o sistema social estão no centro da análise.

O conceito de desinstitucionalização tem base numa análise que considera um declínio das instituições promotoras da coesão na sociedade moderna. Dessa forma, Dubet explica que a sociedade capitalista moderna construiu instituições para solidificar processos de socialização, impondo ao sujeito um lugar de subordinação a elas, para fins de perpetuação do próprio sistema. Segundo ele, essas instituições, na sociedade moderna, não estão para atender as demandas do sujeito, mas, para impor moralização. Assim, passaram, durante muito tempo, a ter um lugar sagrado na sociedade, não passível de questionamento. Frente à força socializadora das instituições, o sujeito tem sua subjetividade objetivada pela coerção social, de modo que ele não se autonomiza do sistema, mas apenas o reflete.

No entanto, Dubet analisa que estamos vivendo um processo de transição entre a sociedade moderna e a contemporânea. Para ele, não se pode mais realizar a análise da sociedade considerando um modelo social pautada na força do estado-nação, na centralidade do trabalho e no poder das instituições.

A experiência social forma-se no caso em que a representação clássica da 'sociedade' já não é adequada, no caso em que os actores são obrigados a gerir simultaneamente várias lógicas da ação que remetem para diversas lógicas do sistema social, que não é então já 
'um' sistema, mas a co-presença de sistemas estruturados por princípios autônomos (Dubet, 1996, p. 94).

Assim sendo, para Dubet, a sociedade contemporânea pós-industrial está assentada em várias lógicas que regulam a vida social, a par do declínio da centralidade do trabalho e das instituições que antes a sustentavam.

O processo de desinstitucionalização, pois, reflete o declínio do monopólio das instituições no processo de socialização dos sujeitos. Para Dubet, esse monopólio vai perdendo consistência, na medida em que vai deixando de se imporcomoinstituição.Analisaque, nacontemporaneidade, ainda que a escola, a igreja e a família tenham importância nos processos de socialização, concorrem com outros espaços socializadores e são enfraquecidos frente a um sujeito com maior autonomia em relação ao sistema; um sujeito que constróis as instituições, ao passo que é construído por ela. Desse modo, ao considerar a dupla influência entre indivíduo e instituição - sendo que, para Dubet, nessa relação é o sujeito quem tem tido maior força determinadora, - já não se pode designar esses espaços socializadores como instituições, simplesmente, porque na contemporaneidade, eles não existem mais como tal.

Desenvolve essa tese a partir da análise histórica sobre as mudanças na configuração da família, da escola e da igreja, pela qual percebe que, em ambas as 'instituições', a dimensão individual do sujeito se impõe, dando-lhe o poder de escolha e o reconhecendo como ator social responsável pela reconstrução das mesmas.

Por isso, para Dubet e, diferente de Bourdieu, mais do que agente, o indivíduo é ator social. Assim sendo, o que move a ação do indivíduo não é o habitus, mas a experiência. Esclarece ainda que essa experiência se processa na medida em que " o actor é obrigado a articular lógicas de ação diferentes, e é a dinâmica gerada por esta actividade que constitui a subjectividade do actor e a sua reflectividade" (Dubet, 1996, p. 107).

Para ele, portanto, o sujeito tem relativa autonomia frente aos processos de objetivação impostos pelo sistema, na medida em que sua experiência pessoal é mediada por lógicas independentes e distintas, que não se reduzem aos condicionamentos do sistema e, muito menos, de um único sistema. Assim, ressalta o autor:

Contra as imagens demasiado claras que opõem a cultura toda-poderosa à razão autônoma, convém antes sublinhar que existe na experiência social alguma coisa de inacabado e de opaco, porque não há adequação absoluta da subjetividade do actor e da objectividade do sistema (Dubet, 1996, p. 96). 
Desse modo, a sociologia da experiência proposta por Dubet define a experiência como uma combinação de lógicas de ação. Isso porque, para Dubet, inspirado em Weber, o sistema também não tem uma unidade, não existindo, "um sistema e uma lógica de ação, mas uma pluralidade não hierárquica” (Dubet, 1996, p. 108, grifo do autor).

Nessa direção, considera que a sociedade não é formada por um princípio de coerência interna, mas por três grandes tipos de sistemas, formados por uma comunidade (integração), por um mercado (competição) e pela cultura. A estes sistemas que são construídos e não naturalmente dados, correspondem três lógicas de ação: a integração, a estratégia e a subjetivação. Para Dubet, a circulação entre essas três lógicas apaga a idéia da sociedade como sistema fechado, como máquina.

$\mathrm{Na}$ lógica da integração, a ação do indivíduo é definida pela integração ao sistema, ou seja, pelos seus vínculos à comunidade. Neste registro da ação, "a identidade é tão-só a maneira como o actor interiorizou os valores institucionalizados por meio dos papéis e [...] a personalidade está mais perto da personagem social" (Dubet, 1996, p. 115). Portanto, nessa lógica a ação é gerida pela incorporação dos códigos sociais que atendem às demandas da integração social.

A lógica da ação regida pela estratégia é definida pelos interesses do ator num mercado concorrencial. Esse é relativo não somente ao domínio econômico, mas ao conjunto das atividades e bens sociais. Nesse sentido, afirma que "a sociedade é vista como um sistema de trocas concorrenciais na competição para se obterem bens raros: o dinheiro, o poder, o prestígio, a influência, o reconhecimento...." (Dubet, 1996, p.115).

Dubet assinala que, ainda que a ação estratégica seja movida por motivações diferentes às da lógica da integração, essa não seria possível sem o apoio de uma integração mínima, visto que essa dá garantia aos jogadores de terem a manutenção das regras que torna o jogo possível. No entanto, isso não significa que estratégia e integração estejam absolutamente articuladas ou confundidas, como o é na teoria de Boudieu. As duas lógicas têm sentidos distintos e assim, mobilizam a ação dos sujeitos para fins também distintos.

Como exemplo, menciona o caso de uma turma escolar infantil. Por um lado, afirma que os alunos descrevem uma comunidade que associa a uma identidade de pertença; uma turma integrada, diferente de todas as outras e dos adultos. Por outro lado, diz que as mesmas crianças descrevem a turma como um grupo marcado por competições permanentes, em que cada um se utiliza de estratégias para perseguir seus interesses individuais e 'egoístas'. Pode-se perceber, por exemplo, que as lógicas se relacionam, comunicam-se, conflitam-se, mas não se 
5 Por alienação Dubet compreende a perda da capacidade de ser sujeito, o que provoca o esvaziamento do sentido da experiência social.

6 Articulado a este princípio de consideração do sujeito como ator social, Dubet, juntamente com seus colegas de filiação teórica, entre eles, seu precursor, Alan Touraine, opera, na escola de CADIS/ Paris, o Método de Intervenção Sociológica. Nesse método, os atores não são apenas sujeitos que fazem relatos, mas, como atores sociais críticos, também fazem análise de seus problemas. Desse modo, esse método consiste em trabalhar em grupo, mas diferenciando-se de grupo focal. Se esse último consiste na realização de entrevista mediada por tema gerador, na qual o pesquisador se isenta de qualquer intervenção, o método de intervenção sociológica deseja provocar o confronto, de maneira a colocar diferentes sujeitos (professores, alunos, psicólogos, etc..) para motivar o debate, enriquecido por posicionamentos construídos de diferentes lugares. O papel do pesquisador, nesse caso, não é de ficar isento do debate, mas, de construir a análise sociológica do trabalho do grupo. Essa metodologia repousa na dupla recusa. Por um lado, a recusa por uma visão que tende a perceber os sujeitos como 'idiotas sociológicos', como se não fossem capazes de fazer análise dos problemas sociais aos quais estão implicados. Por outro lado, a recusa pelo subjetivismo social que anula a função do pesquisador. $\mathrm{Na}$ concepção desse método, é esse que tem o papel de enriquecer o debate com lentes de interpretação pautadas numa análise sociológica. anulam, uma vez que têm sentido diferentes para o ator que por elas mobiliza a ação.

Já a lógica da subjetivação é movida pelos interesses e motivações subjetivas do ator. É por meio dessa lógica que o ator se coloca como sujeito crítico frente a uma sistemática de dominação e alienação. Por isso, Dubet assinala que ela não é vivida de foram positiva como as outras, mas está em constante tensão com a integração e a estratégia.

No entanto, para Dubet, é pela subjetivação que o ator se experiencia como tal, pela qual dá para se falar em uma lógica do sujeito. Para ele, uma lógica do sujeito se manifesta de forma "indirecta na atividade crítica, aquela que supõem que o actor não é redutível nem aos seus papéis nem aos seus interesses, quando ela adopta um ponto de vista diferente do da integração e da estratégia"( Dubet, 1996, p. 130).

É, pois, por meio da experiência subjetiva que o ator se experiencia como sujeito, lutando contra a alienação ${ }^{5}$. Nesse sentido, Dubet também conceitua a subjetividade como a atividade social que manifesta a perda da adesão à ordem do mundo, pela qual o sujeito constrói a afirmação de sua identidade. Essa, por sua vez, "[...] é formada pela sua tensão com o mundo, quer dizer, com a ação integradora e com a estratégia" (Dubet, 1996, p. 131).

Contudo, Dubet alerta sobre o risco que se corre de interpretar a experiência social como uma noção propriamente subjetiva e descolada do sistema social, ou seja, essencialista. Sem cair no estruturalismo da sociologia clássica, uma vez que não postula, em nenhum momento, o pressuposto de uma unidade na ação ou de uma hierarquia funcional das diversas lógicas do sistema, afirma que, em sentido muito geral, é sempre possível considerar que a acção é a vertente subjectiva do sistema. Desse modo, conclui que "as experiências sociais são combinações subjetivas de elementos objectivos" ( Dubet, 1996, p. 140).

Outrossim, é a capacidade de ação do ator que permite falar em uma subjetividade que não seja reduzida a ação do sistema.

O actor constrói uma experiência que lhe pertence, a partir de lógicas da acção que lhe não pertencem e que lhe são dadas pelas diversas dimensões do sistema que se separam à medida que a imagem clássica da unidade funcional da sociedade se afasta (Dubet, 1996, p.140).

Não obstante, cabe lembrar que, para Dubet, a experiência social é socialmente construída e é crítica. Isso significa dizer que tanto não existe experiência individual 
7 O liceu, na França, refere-se, em analogia ao sistema brasileiro, ao segundo grau. É o último ciclo da formação básica. Ele compreende dois tipos de formação: uma de caráter técnico-profissionalizante e outra de caráter mais científico e preparatório para o terceiro grau. Antes dos anos 50, a seleção dos alunos para decidir o tipo de formação no liceu e o acesso ao ensino superior, era realizada pelo critério de mérito do histórico escolar do aluno. Com a democratização, o aluno é submetido a exames no final de cada ciclo, o que, supostamente, dá uma aparência de democratização ao acesso, já que todos são submetidos ao mesmo exame. $\mathrm{O}$ resultado dos exames vai definir o direito ao ingresso no terceiro grau, bem, como, o tipo de curso freqüentado. Bourdieu mostra, a partir de dados estatísticos, que, na prática, a realidade não mudou, uma vez que continua a mesma relação entre classe social e escolaridade. As classes populares, geralmente, não ultrapassam a formação técnico-profissionalizante, enquanto que as médias e elites continuam a ter garantido o acesso ao terceiro grau e à formação complementar (pós-graduação) (Bourdieu, 1998). pura, isolada das relações sociais como também o sujeito é capaz de dominar conscientemente, em certa medida, a sua relação com o mundo. ${ }^{6}$

\section{PARA CONCLUIR:O SENTIDO DA ESCOLA, SÍNTESES E CONTRAPONTOS}

Para finalizar e apontar alguns contrapontos entre os dois autores aqui abordados, trago alguns elementos no sentido de sintetizar possíveis respostas para a questão que mobilizou este ensaio: o que move a ação dos indivíduos? Ainda nesse exercício de síntese e contrapontos, fiquei muito mobilizada em apresentar, sucintamente (uma vez que se trata de um item conclusivo) alguns elementos teóricos - obviamente relacionados aos conceitos centrais aqui trabalhados - que fazem relação à forma como os respectivos autores analisam o sentido da escola na formação dos sujeitos.

Com efeito, a partir do estudo dos dois autores destaquei, em cada um, o conceito central pelo qual buscam compreender a ação dos indivíduos.

Assim é que, o primeiro - Pierre Bourdieu - percebe o sujeito como um agente mobilizado por um habitus que lhe é construído, inconscientemente, através de suas relações com o contexto de classe. Sendo assim, o agente mobiliza sua ação tendendo a permanecer na mesma posição social de origem, contribuindo, dessa forma, para a reprodução social.

Já o segundo - Dubet - percebe o sujeito como um ator social, crítico e conscientemente capaz de construir sua própria experiência social, essa que é fruto da tensão entre três lógicas, pelas quais o ator se movimenta e escolhe: a integração, a estratégia e a subjetivação. Desse modo, a experiência individual é construída num jogo de relações sociais, essas relacionadas a um sistema heterogêneo, com o qual o sujeito tem possibilidade de distanciamento e crítica.

Esses dois conceitos - de habitus e de experiência também são considerados pelos dois respectivos autores na forma de analisar as relações com a escola.

Assim, Bourdieu procura demonstrar como a escola produz desigualdades e contribui para a reprodução social.

Desse modo, questiona duramente alguns pressupostos que a escola buscou construir como promotores de igualdade. Por exemplo, no texto: Excluídos do Interior, realiza uma espécie de desmascaramento da escola, demonstrando que essa, mesmo com o processo de democratização que se deu na França a partir dos anos 50 dando, 'a todos', o direito de cursar o liceu e a pleitear vaga num curso de terceiro grau', continua a produzir 
exclusão, mas de forma camuflada. Alega que a suposta democratização não veio, de forma alguma a gerar igualdade de êxito na carreira escolar. Muito pelo contrário, na medida em que a escola passa a desconsiderar as diferenças de capital econômico e cultural dos alunos e passa a avaliálos em função do mérito individual, delegando a esses a responsabilidade pelo seu insucesso, acaba produzindo em seu interior uma lógica mais sofisticada de exclusão: aquela que inclui excluindo.

Bourdieu, dessa forma, realiza forte crítica à ideologia do dom, a partir da qual se velam os mecanismos de reprodução, legitimando as desigualdades escolares e, consequentemente, sociais. A escola, camuflada sob a justificativa do dom, transforma diferenças sociais em diferenças escolares, exercendo, segundo Bourdieu, uma função mistificadora.

Além de permitir à elite se justificar de ser o que é, 'a ideologia do dom', chave do sistema escolar e do sistema social, contribui para encerrar os membros das classes desfavorecidas no destino que a sociedade lhes assinala, levando-os a perceberem como inaptidões naturais o que não é senão efeito de uma condição inferior, e persuadindo-os de que eles devem o seu destino social (cada vez mais estreitamente ligado ao seu destino escolar, à medida em que a sociedade se racionaliza) - à sua natureza individual e à sua falta de dons. (Bourdieu, 1998, p. 59).

Em síntese, o sentido da escola para Boudieu já está dado a priori e é, por essência, desigual, mudando conforme a origem social do aluno. O seu habitus de classe (aqui importa, principalmente, o nível de seu capital cultural) o leva a interiorizar as chances objetivas e a aceitarse como um sujeito que já está escrito numa determinada classe social, cuja ascensão será quase impossível.

Já Dubet está interessado em compreender o que a escola 'fabrica' nos indivíduos e, assim, como esses vivem a experiência escolar.

Para ele, a escola não reproduz apenas desigualdades, mas produz diferenças de ordem simbólica. Isso porque, para Dubet, o sentido da escola é dado pelo ator, na medida em que esse constrói sua experiência subjetiva com ela. A experiência do sujeito por sua vez, não está restrita a lógica da reprodução social, como o estaria em Boudieu. Esse é resultado da relação de três lógicas que mobilizam sua ação: a integração, a estratégia e a subjetivação. Estas lógicas derivam da articulação do sujeito ao sistema, de um lado e, por outro, da relativa autonomia deste sobre ele. 
Em pesquisa realizada juntamente com Martuccelli (1998), na qual se dedicam a refletir sobre a experiência escolar vivida nos três níveis de ensino - primário, colégio e liceu - torna-se bastante visível que essa é diferentemente construída pelos atores, na medida em que articulam diferentes lógicas.

Evidenciam que, na escola elementar (primário), a experiência dos atores (alunos, professores e pais) é fortemente estruturada pela lógica da integração. É, pois, o nível em que a escola mais consegue se impor como instituição socializadora. Já no colégio, observa um distanciamento maior com os processos de socialização, de modo que os alunos passam a se colocar mais criticamente frente às normas escolares. Porém, observa que a resistência à escola é vivida diferentemente dependendo do contexto escolar. Desse modo, observa maior resistência por parte dos alunos do colégio de periferia do que de classe média. Já no liceu, observa que a experiência se torna mais complexa e é vivida de foram muito diferente dependendo do tipo de liceu frequentado. Assim, os processos de subjetivação dos alunos se conflitam, na medida em que esses vivem uma forte tensão entre vocação e utilidade/estratégia. (Dubet e Martuccelli, 1998).

Dessa forma, para Dubet, a escola não pode ser vista como um sistema homogêneo, uma vez que produz experiências muito diferenciadas em seu interior. Isso incita para que se pense na escola no plural - de modo que se admita a existência de Escolas - bem como, se considere o princípio da diversidade de seus atores (alunos, professores e pais) e de suas experiências escolares.

Enfim, nota-se que as diferentes visões sobre a ação humana e o sentido da escola apresentados aqui, estão diretamente articuladas à forma como os autores compreendem as relações entre sistema social e sujeito, estas, notadamente, ligadas a filiações teóricas distintas. Ambos fornecem importantes contribuições no sentido de indicar possíveis 'faróis de análise' para refletir sociologicamente as inúmeras e complexas questões que envolvem a educação e a sociedade na contemporaneidade.

\section{REFERÊNCIAS}

BONNEWITZ, Patrice. Primeiras lições sobre a sociologia de Pierre Bourdieu. Petrópolis/RJ: Vozes, 2005 .

BOURDIEU, Pierre. Leshéritiers (Os herdeiros). Paris: Ed. de Minuit, 1964.

A reprodução: elementos para uma

teoria do sistema de ensino. Lisboa: Editorial Vega, 1978. 
BOURDIEU, Pierre. Questões de sociologia. Rio de Janeiro: Marco Zero Limitada, 1983.

Escritos de Educação. In: NOGUEIRA, Maria Alice e CATANI, Afrânio (orgs.). Escritos de Educação. Petrópolis: Vozes, 1998.

Os excluídos do interior. In: NOGUEIRA, Maria Alice e CATANI, Afrânio (orgs.). Escritos de Educação. Petrópolis: Vozes, 1998.

As contradições da herança. In: NOGUEIRA, Maria Alice e CATANI, Afrânio (orgs.). Escritos de Educação. Petrópolis: Vozes, 1998.

DUBET, François. Sociologia da Experiência. Lisboa: Instituto Piaget, 1996. (França: Seuil, 1994).

DUBET, François; MARTUCELLI, Danilo. Em La escuela - sociologia de la experiência escolar. Buenos Aires: Losada, 1998. (França: Seuil, 1996).

LAHIRE, Bernard. A cultura dos indivíduos. Porto Alegre: Artmed, 2006. 